\title{
Transcranial magnetic stimulation research on reading and dyslexia: a new clinical intervention technique for treating dyslexia?
}

\author{
Maurits van den Noort ${ }^{1,2}$, Esli Struys ${ }^{1}$, Peggy Bosch ${ }^{2,3,4}$ \\ ${ }^{1}$ Department of Linguistics, Vrije Universiteit Brussel, 1050 Brussels, Belgium. \\ ${ }^{2}$ Research Group of Pain and Neuroscience, Kyung Hee University, Seoul 130-701, South Korea. \\ ${ }^{3}$ Centre for Cognition, Donders Institute for Brain, Cognition and Behaviour, Radboud University Nijmegen, 6500 GL Nijmegen, \\ Gelderland, the Netherlands. \\ ${ }^{4}$ Psychiatric Research Institute, LVR-Klinik Bedburg-Hau, 47551 Bedburg-Hau, Germany.
}

\section{A B S T R A C T}

\begin{abstract}
Nowadays, several noninvasive neuroimaging techniques, including transcranial magnetic stimulation (TMS), exist. The working mechanism behind TMS is a rapidly changing magnetic field that generates an electric current via electromagnetic induction. When the coil is placed on the scalp, the magnetic field generates a physiological reaction in the underlying neural tissue. The TMS-induced change in the participant's behavior is used by researchers to investigate the causal relations between specific brain areas and cognitive functions such as language. A variant of TMS has been developed, which is called rapid-rate TMS (rTMS). In this review, three databases (Medline, Educational Resources Information Center, and Scopus) were searched for rTMS studies on normal reading and dyslexia with a cut-off date of October 31,2014. rTMS was found to be a valuable tool for investigating questions related to reading research, both on the word and the sentence level. Moreover, it can be successfully used in research on dyslexia. Recently, (high-frequency) rTMS has been used as a "clinical" intervention technique for treating dyslexia and for improving reading performance by exciting underactive reading pathways in the brain. Finally, we end the paper with a discussion of future directions in the field of rTMS research and dyslexia, for instance, the promising prospect of combining TMS with simultaneous electroencephalographic imaging.
\end{abstract}

Key words: Clinical intervention, dyslexia, sentence reading, transcranial magnetic stimulation, word reading

\section{INTRODUCTION}

\section{Transcranial magnetic stimulation}

Nowadays, (cognitive) neuroscientists can choose from several noninvasive neuroimaging techniques, and one of them is transcranial magnetic stimulation (TMS). The working mechanism behind TMS is a rapidly changing magnetic field that generates an electric current via electromagnetic induction. ${ }^{[1]}$ When the coil is placed on the scalp, the magnetic field generates a physiological reaction in the underlying neural tissue, ${ }^{[2]}$ which can be a spiking and/or a depolarizing reaction, ${ }^{[3,4]}$ and specific or general areas of the brain can be affected. Transient noise is introduced into the

\begin{tabular}{|l|l|}
\hline \multicolumn{2}{|c|}{ Access this article online } \\
\hline Quick Response Code: & Website: \\
\hline & www.nnjournal.net \\
\hline & \\
\hline
\end{tabular}

neural computation being performed, often leading to longer reaction times or higher error rates. ${ }^{[2]}$

As early as 1985, the first successful TMS study on human participants was conducted by Barker et al..$^{[5]}$ The authors described the use of a pulsed magnetic field focused over specific regions of the cerebral cortex to induce muscle action potentials (see also the publication by Barker et al. ${ }^{[6]}$ later that year). In fact, their pioneering study turned out to be the beginning of a whole new research field. This TMS-induced change in the participant's behavior is an interesting opportunity for researchers to study the causal relations between specific brain regions and cognitive functions. ${ }^{[7]}$

\section{Rapid-rate transcranial magnetic stimulation}

Later, a variant of TMS was developed, which is called rapid-rate TMS (rTMS). ${ }^{[8,9]}$ Further improvements of the stimulators, which are now able to provide discharges at frequencies of up to $60 \mathrm{~Hz}$, have greatly increased the value of TMS as a tool in cognitive neuroscience 
research. ${ }^{[10]}$ By varying the intensity, stimulation frequency, and duration of rTMS, the researcher can now transiently inhibit or block the function of a specific cortical structure or enhance the excitability of particular cortical areas under the coil. ${ }^{[10-12]}$ Moreover, in addition to the useful applications of rTMS in basic cognitive neuroscience research, clinicians have recently started to use it as a therapeutic technique. ${ }^{[13]}$ Later, in this paper, we will look into the possibility of using rTMS as a therapeutic intervention for treating dyslexia.

First transcranial magnetic stimulation studies on language The first TMS study on language was conducted by Pascual-Leone et al., ${ }^{[14]}$ who induced speech arrest in presurgical patients with epilepsy. They were particularly interested in whether TMS could be used as an alternative to intracarotid amobarbital testing, also known as the WADA-test, ${ }^{[15]}$ which is a test that is clinically used to determine language representation in presurgical patients, but can lead to several substantial negative side effects (like seizures, encephalopathy, strokes, etc.).[16]

In the last two decades, TMS studies on language have further focused on language representation issues; ${ }^{[17]}$ moreover, the identification of language areas and an understanding of their underlying functions have become key research topics. ${ }^{[18]}$ TMS is used to either inhibit or facilitate language processes and may operate directly on a specific language-related cortex area or indirectly via the intra-cortical networks. With TMS, reversible temporary lesions have been made in order to investigate the cerebral cortical areas that are thought to be responsible for language function. Interestingly, the TMS results differ from those predicted by classical models of language organization: speech production in the left inferior frontal region ${ }^{[19]}$ and reception of language in the superior temporal gyrus. ${ }^{[20]}$ RTMS over the left inferior frontal region was found to block speech output while speech arrest was obtained most easily over the facial motor-cortex, a structure located anterior to the central sulcus and superior to the perisylvian fissure. Surprisingly, in general, the rTMS results show limited proof for aphasia as a result of impairment of the classical Broca's left inferior frontal region $^{[19]}$ and of Wernicke's superior temporal gyrus, ${ }^{[20]}$ whereas right-hemisphere or bilateral lateralization was often found. ${ }^{[18]}$

\section{Aim of the study and methodology used}

The aim of the present paper was to review the use of TMS in the study of, as well as its role in developing a better understanding of, one specific language area, namely, reading. What are the contributions of TMS to the understanding of the different reading modalities? After discussing the main findings of TMS research on normal readers, we will look deeper into the field of TMS and dyslexia. We will finish our paper by answering the question whether rTMS can be used as a future therapeutic modality for treating dyslexia.

The following methodology was used in the present review. Three databases (Medline, ${ }^{[21]}$ Educational Resources Information Center, ${ }^{[22]}$ and Scopus ${ }^{[23]}$ ) were searched with a cut-off date of October 31, 2014. In addition, the reference lists of all studies that were found in the databases were further checked in order to find additional suitable studies (also known as the snowball method).[24] Two authors (van den Noort and Struys) independently performed the literature search; moreover, the study selection and data extraction were also independently conducted by two authors (van den Noort and Struys). The extracted data included the authors, the title, the journal in which the study had been published, the publication year, the number of participants involved in the study, the exact methodology used, the effects of TMS on normal reading and in treating dyslexia that were found, and the conclusions that were drawn. In addition, Bosch was contacted in case of disagreement regarding the study selection and/or data extraction, and in all cases, a consensus was reached.

\section{TMS RESEARCH ON NORMAL READING}

First, we will discuss several influential TMS studies involving normal readers and focusing on the processing of words and Chinese characters. Then, we will move on to the sentence-level. Note that the processing of words/characters is a simplification of reading in daily life, where complete sentences and texts are processed. However, for reading research, these studies are relevant because they give important insights into how normal reading works, and as we will see later in this paper, can explain what has gone wrong in individuals with dyslexia.

\section{Word-level}

\section{Visual word recognition}

Before the advent of TMS, behavioral studies of visual word recognition had already suggested that the left cerebral hemisphere was more critically involved in visual word recognition than the right cerebral hemisphere. Participants showed slower reading times for longer words than for shorter words (a phenomenon known as the "word-length reading effect") when the words were presented in the left-hemi-field, as a result, were processed in the right hemisphere (note that the human visual system is contra-lateral in nature $\left.{ }^{[25]}\right)$, but this was not the case when the words 
were presented in the right-hemi-field, and as a result, were processed in the left-hemisphere (a phenomenon known as "length-independent reading"), ${ }^{[26]}$ proving the hypothesis that the left cerebral hemisphere is more critically involved in visual word recognition.

Skarratt and Lavidor ${ }^{[27]}$ were the first to test these behavioral findings ${ }^{[26]}$ with rTMS. They were particularly interested in how expert readers were able to identify arrays of several letters quickly and in parallel. They found that left occipital cortex rTMS disrupted processing in the right visual hemi-field of experts, resulting in the previously-discussed word-length reading effect. RTMS of the right occipital cortex, however, did not disrupt the processing of right visual hemi-field words in experts nor did it affect the word-length reading effect that was already visible in the left visual hemi-field. To conclude, Skarratt and Lavidor's study ${ }^{[27]}$ were the first to demonstrate that TMS-induced impairment in the left-hemisphere led to a word-length reading effect, providing neuroscientific evidence for the hypothesis that the left-hemisphere is more specialized in word recognition [Table 1].

In addition, several studies have tested these visual hemi-field word processing findings ${ }^{[26,27]}$ by using foveally-presented lexical stimuli ${ }^{[28,29]}$ and have revealed that the different right and left-hemispheric processing styles have contra-lateral influences on the responses driven by the right and the left halves of the lexical stimuli (also known as the split fovea theory). ${ }^{[30]}$ In sum, research has shown the importance of human foveal splitting for the visual recognition of words, ${ }^{[31]}$ but the question of what would happen in
Chinese character recognition remained? Therefore, an intriguing study on human foveal splitting with rTMS was conducted by Hsiao et al., ${ }^{[32]}$ in which not words, but Chinese characters were used as stimuli. As in Skarratt and Lavidor's rTMS study, ${ }^{[27]}$ Hsiao et al. ${ }^{[32]}$ conducted rTMS on the right and the left occipital cortexes. Hsiao et al. ${ }^{[32]}$ found neuroscientific proof for the split fovea theory. ${ }^{[30]}$ Moreover, with respect to visual word recognition, they showed that fovea splitting was not a unique characteristic of European languages, but could also be found in Chinese, which belongs to a completely different language family and uses characters instead of Arabic letters. ${ }^{[32]}$

In their TMS study, Stoeckel et al. ${ }^{[33]}$ were particularly interested in the supramarginal gyrus. Previous neuroimaging research had shown that the supramarginal gyrus played a role in visual word recognition. ${ }^{[34]}$ Stoeckel et al. ${ }^{[33]}$ were the first to use the TMS technique to investigate the role of the supramarginal gyrus in word recognition. They used three different tasks: a phonological, a semantic, and a visual control task. Their results showed that the supramarginal gyrus contributed to reading, regardless of the specific task requirements. The supramarginal gyrus automatically seemed to compute the sound of the word, even when it was not needed for the task. ${ }^{[33]}$ Thus, the visual perception of words automatically seemed to activate the auditory representation of their spoken forms. ${ }^{[33]}$

Nakamura et al. ${ }^{[35]}$ further investigated the above issue by conducting TMS on both the left superior temporal

\begin{tabular}{|c|c|c|c|}
\hline Study & Participants & Brain area & Main finding \\
\hline $\begin{array}{l}\text { Skarratt and } \\
\text { Lavidor }^{[27]}\end{array}$ & $\begin{array}{l}\text { Twelve right-handed, } \\
\text { healthy, volunteers }\end{array}$ & $\begin{array}{l}\text { Occipital } \\
\text { cortex }\end{array}$ & $\begin{array}{l}\text { A word-length effect was found after rTMS had been conducted on } \\
\text { the left occipital cortex. Evidence was found for the hypothesis that } \\
\text { the left-hemisphere was more specialized in word recognition }\end{array}$ \\
\hline Hsiao et al. ${ }^{[32]}$ & $\begin{array}{l}\text { Eight right-handed, } \\
\text { healthy, volunteers, who } \\
\text { were all native speakers of } \\
\text { Chinese }\end{array}$ & $\begin{array}{l}\text { Occipital } \\
\text { cortex }\end{array}$ & $\begin{array}{l}\text { The findings of the Chinese character study confirmed the split } \\
\text { fovea hypothesis. Moreover, it showed that fovea splitting was not } \\
\text { solely found for reading in European languages, but seemed to be a } \\
\text { universal processing constraint }\end{array}$ \\
\hline Stoeckel et al..$^{[33]}$ & $\begin{array}{l}\text { Twenty-two right-handed, } \\
\text { healthy volunteers, who } \\
\text { were all native English } \\
\text { speakers }\end{array}$ & $\begin{array}{l}\text { Supramarginal } \\
\text { gyrus }\end{array}$ & $\begin{array}{l}\text { The authors found that the supramarginal gyrus clearly contributed } \\
\text { to reading; moreover, a conclusion was that the supramarginal gyrus } \\
\text { automatically computed the sound of a word and that this occurred } \\
\text { even when it was not really required to perform the task }\end{array}$ \\
\hline Nakamura et al. ${ }^{[35]}$ & $\begin{array}{l}\text { In total, } 30 \text { healthy, native } \\
\text { Japanese speakers }\end{array}$ & $\begin{array}{l}\text { Superior } \\
\text { temporal gyrus } \\
\text { and inferior } \\
\text { parietal lobe }\end{array}$ & $\begin{array}{l}\text { A clear double dissociation was discovered; the repetition priming } \\
\text { during the pronunciation task was eliminated when TMS was } \\
\text { conducted on the left inferior parietal lobe, but not when it was } \\
\text { conducted on the left superior temporal gyrus, whereas the priming } \\
\text { during the lexical decision task was eliminated when the left superior } \\
\text { temporal gyrus, but not the left inferior parietal lobe, was stimulated }\end{array}$ \\
\hline Tomasino et al. ${ }^{[36]}$ & $\begin{array}{l}\text { Twenty right-handed, } \\
\text { healthy men, who were all } \\
\text { native speakers of German }\end{array}$ & $\begin{array}{l}\text { Primary } \\
\text { motor-cortex }\end{array}$ & $\begin{array}{l}\text { The authors showed that the primary motor-cortex was critically } \\
\text { involved in processing action verbs, but that this was only the case } \\
\text { when participants were simulating the corresponding movement }\end{array}$ \\
\hline Hoffman et al. ${ }^{[37]}$ & $\begin{array}{l}\text { Thirteen right-handed, } \\
\text { healthy, native speakers of } \\
\text { English }\end{array}$ & $\begin{array}{l}\text { Ventrolateral } \\
\text { prefrontal } \\
\text { cortex }\end{array}$ & $\begin{array}{l}\text { The results suggested that the ventrolateral prefrontal cortex worked } \\
\text { as a kind of executive regulator in the processing of abstract words. } \\
\text { However, this was less the case when abstract words were presented } \\
\text { in a specific context and when concrete words were processed }\end{array}$ \\
\hline
\end{tabular}


gyrus and the inferior parietal lobe. In their study, they used auditory and visual targets and a pronunciation and lexical decision task. Nakamura et al. ${ }^{[35]}$ discovered a clear double dissociation. On the one hand, the repetition priming during the pronunciation task was eliminated when TMS was conducted on the left inferior parietal lobe, but not when it was conducted on the left superior temporal gyrus. On the other hand, the priming during the lexical decision task was eliminated when TMS was conducted on the left superior temporal gyrus, but not when it was conducted on the left inferior parietal lobe [Table 1]. ${ }^{[35]}$

\section{Reading action verbs}

So far, we have discussed TMS studies on general visual word recognition; however, from a neurolinguistic point of view, the study of what happens in the brain when a specific type of verb is read, namely, an "action verb", is also interesting. These verbs all express some kind of action. Tomasino et al. ${ }^{[36]}$ applied TMS to the hand area of the left primary motor cortex during experimental trials of three different tasks (silent reading of action verbs, motor imagery of the action, and frequency judgment) and to the vertex during the control trials of these tasks. The authors found neuroscientific evidence for the hypothesis that the primary motor cortex was critically involved in processing action verbs but that this was only the case when the participants were simulating the corresponding movement. ${ }^{[36]}$

\section{Abstract versus concrete words}

Another important neurolinguistic word class distinction, besides the previously-discussed "action verbs", can be made between the so-called "concrete" words (an example is the word tree) and "abstract" words (an example is the word love). In a rTMS study, Hoffman et al..$^{[37]}$ investigated the idea that abstract words depended on the ventrolateral prefrontal cortex for understanding, as was previously suggested based on neuroimaging findings. ${ }^{[38]}$ The authors hypothesized that an increase in the executive regulation would be needed as a result of the various meanings abstract words could have, depending on the context. Their results, indeed, suggested that the ventrolateral prefrontal cortex worked as a kind of executive regulator in abstract word processing. However, this was less the case when the abstract words were processed within a particular context because then the system was already guided in the direction of a specific meaning or interpretation. In contrast, regulation played a smaller role in the processing of concrete words because in the processing of concrete words, the number of possible meanings are already decreased as a result of their physical referents; moreover, their meanings did not differ in various contexts. ${ }^{[37]}$

\section{Sentence-level}

Having discussed the main results that were found on the word-level in normal readers using TMS, we will now discuss the main findings that were found on the sentence-level. Note that these studies are closer to real language situations, for instance, situations in which people are reading books or newspapers.

\section{Sentence comprehension}

Manenti et $a 1 . .^{[39]}$ conducted an rTMS study on sentence reading [Table 2]. They were particularly interested in if and how a specific area in the brain, the dorsolateral prefrontal cortex, was involved in the understanding of sentences. It had previously been suggested that dorsolateral prefrontal cortex engagement might reflect the working memory load in sentence processing. ${ }^{\left[{ }^{[0,41]}\right.}$ Manenti et al. ${ }^{[39]}$ found that when rTMS was conducted on the left dorsolateral prefrontal cortex, the participants needed more time to complete a semantic task (i.e. was the meaning of the sentence correct or not), but not to complete a syntactic task (i.e. was the grammar of the sentence correct or not). Furthermore, when rTMS was conducted on the right dorsolateral prefrontal cortex, the opposite pattern was visible, and the participants needed more time to finish the syntactic task, but did not need more time

\begin{tabular}{|c|c|c|c|}
\hline Study & Participants & Brain area & Main finding \\
\hline Manenti et al. ${ }^{[39]}$ & $\begin{array}{l}\text { Twelve right-handed, } \\
\text { native Italian speakers }\end{array}$ & $\begin{array}{l}\text { Dorsolateral } \\
\text { prefrontal } \\
\text { cortex }\end{array}$ & $\begin{array}{l}\text { A double dissociation between the type of task (semantic vs. } \\
\text { syntactic) and the rTMS effects was found, supporting the idea } \\
\text { that the underlying working memory resources in sentence } \\
\text { comprehension were processed differently by the two hemispheres }\end{array}$ \\
\hline Cacciari et al..$^{[42]}$ & $\begin{array}{l}\text { Nine healthy } \\
\text { participants }\end{array}$ & Motor area & $\begin{array}{l}\text { The activity of the motor areas was affected by the motor } \\
\text { component of the verb. This phenomenon was visible when fictive } \\
\text { and metaphorical motion sentences were processed }\end{array}$ \\
\hline Scorolli et al. ${ }^{[43]}$ & $\begin{array}{l}\text { Sixteen healthy, } \\
\text { right-handed, native } \\
\text { Italian speakers }\end{array}$ & $\begin{array}{l}\text { Primary } \\
\text { motor-cortex }\end{array}$ & $\begin{array}{l}\text { Early activation of the hand-related motor system was found after } \\
\text { reading phrases with concrete verbs whereas a delay in the same } \\
\text { region was visible after reading phrases with abstract verbs }\end{array}$ \\
\hline $\begin{array}{l}\text { Acheson and } \\
\text { Hagoort }\end{array}$ & $\begin{array}{l}\text { Twenty participants in } \\
\text { the TMS group and } 20 \\
\text { in the control group }\end{array}$ & $\begin{array}{l}\text { Inferior } \\
\text { frontal gyrus } \\
\text { and middle } \\
\text { temporal gyrus }\end{array}$ & $\begin{array}{l}\text { Their results supported the idea that the middle temporal gyrus } \\
\text { was involved in the retrieval of lexical-syntactic information } \\
\text { whereas the inferior frontal gyrus played a key role in the } \\
\text { unification processes required in order to understand sentences }\end{array}$ \\
\hline
\end{tabular}

rTMS: rapid-rate transcranial magnetic stimulation; TMS: transcranial magnetic stimulation 
on the semantic task. In sum, a double dissociation between the type of task (semantic versus syntactic) that was performed and the rTMS effects was found in this study and provided neuroscientific proof for the hypothesis that the underlying working memory resources in sentence comprehension were processed differently by the two hemispheres. ${ }^{[39]}$

\section{Processing of specific sentence types}

So far, we have discussed general sentence comprehension in normal readers. In contrast to Manenti et al., ${ }^{[39]}$ Cacciari et al. ${ }^{[42]}$ were interested in how readers process specific kinds of sentences. They investigated three neurolinguistic classes of sentences, "literal", "nonliteral" (i.e. metaphorical, idiomatic), and "fictive" motion sentences, and wondered how these different types of sentences affected the excitabilities of the motor areas in the brain. Larger motor-evoked potentials were found when individuals read literal, fictive, and metaphorical motion sentences than when they read idiomatic motion or mental sentences. Cacciari et al. ${ }^{[42]}$ found neuroscientific evidence for the hypothesis that the activity of the motor areas was affected by the motor component of the verb when reading fictive and metaphorical motion sentences.

In line with the study by Cacciari et al., ${ }^{[42]}$ Scorolli et al. ${ }^{[43]}$ were also interested in the motor-cortex involvement underlying sentence comprehension; more precisely, the focus of their study was on the specific role of abstract versus concrete verbs in this process. As Scorolli et al. ${ }^{[43]}$ had hypothesized, early activation of the hand-related motor system was found after reading phrases with concrete verbs, whereas a delay in the same region was visible after reading phrases with abstract verbs. ${ }^{[43]}$

Finally, in their TMS study on normal readers, Acheson and Hagoort ${ }^{[44]}$ were interested in the processing of different kinds of sentences, namely, the so-called: "ambiguous" and "unambiguous" sentences. More precisely, they tested the hypothesis that the middle temporal gyrus played a significant role in the selection and the integration of lexical-syntactic information whereas the inferior frontal gyrus was involved in the unification processes needed for the successful understanding of sentences. Their results, ${ }^{[44]}$ indeed, supported the idea that the middle temporal gyrus was involved in the retrieval of lexical-syntactic information and that the inferior frontal gyrus was involved in the unification processes underlying the successful understanding of sentences.

So far, we have seen that rTMS has become a valuable neuroscientific tool for answering questions related to reading research, both on the word and the sentence-level. However, all the studies and the findings that we have discussed so far were rTMS studies conducted on normal readers who were not experiencing any reading problems. In the second part of our paper, we will address whether rTMS can also be successfully applied to research on individuals that are known to have reading problems? In order to do so, we will discuss TMS studies on dyslexia. In addition, we will go one step further and address whether rTMS can be used as a clinical intervention technique to overcome reading problems?

\section{TMS AND DYSLEXIA}

\section{Dyslexia}

Dyslexia (also referred to as specific reading disability $)^{[45,46]}$ occurs when a child or adult has significant difficulty with the speed and the accuracy of word decoding, which may lead to decreased text comprehension. ${ }^{[4]}$ In addition, spelling difficulties are common in dyslexia [Figure 1]. ${ }^{[48,49]}$ Previous research showed that dyslexia was stable, meaning that children who were identified as dyslexic were likely to continue suffering from reading difficulties throughout their lives. ${ }^{[50,51]}$ The exact prevalence of dyslexia worldwide is unknown; however, in most studies, the prevalence of dyslexia is estimated to be somewhere between $5 \%$ and $10 \%$ of the population. ${ }^{[52]}$ There is no cure for dyslexia, but phonics-based treatments seem to be most successful. ${ }^{[53]}$ Furthermore, in recent years, several treatment variants using temporal-auditory, articulatory, or multisensory exercising programs have been developed in order to help individuals with dyslexia. ${ }^{[54]}$

\section{TMS research on dyslexia}

One of the first TMS studies on dyslexia was conducted by Coslett and Monsul ${ }^{[55]}$ who investigated the hypothesis that the right-hemisphere mediated the reading of patients with acquired dyslexia. A 57-year-old man with (partially recovered) pure alexia participated in the study. The participant's task was to read aloud words that were presented briefly, while receiving TMS on either the right or the left hemisphere. The results of the study supported the right-hemisphere reading hypothesis because stimulation of the right, but not the left, hemisphere affected oral reading. Moreover, this study showed that TMS could be used successfully to answer experimental research questions on dyslexia.

\begin{tabular}{|lcr|}
\hline Normal reader & Word-level & Sentence-level \\
Reading $\quad$ It is easy to read this sentence
\end{tabular}

Figure 1: Examples of how a normal reader and a reader with dyslexia would read the same words and sentences 
However, long time would elapse before researchers started to use TMS not only for basic research on dyslexia but also for clinical applications.

\section{TMS as clinical intervention technique}

Within TMS protocols, Frye et al. ${ }^{[56]}$ were the first to hypothesize that high-frequency repetitive TMS could improve reading performance in people suffering from dyslexia by exciting underactive reading pathways in the brain. Previous neuroscientific research had shown that an improvement in reading in dyslexics was mediated by an increase in the activations of typically hypoactive left-hemisphere areas (also referred to as “normalization”) and by additional activation in the right hemisphere regions (also referred to as "compensation"). ${ }^{[57]}$

Costanzo et al. ${ }^{[58]}$ conducted an intriguing study with high-frequency rTMS on 10 dyslexic adults, who were native speakers of Italian, to test the hypothesis of exciting underactive reading pathways in dyslexics. ${ }^{[56]}$ They conducted $5-\mathrm{Hz}$ TMS over both the left and the right inferior parietal lobules and the superior temporal gyrus (note that these areas had previously been found to improve reading in a TMS study on nondyslexics ${ }^{[59]}$ ) in advance of reading words, nonwords, and text aloud. The results of the study showed that on the one hand, high-frequency rTMS stimulation over the left inferior parietal lobule led to a better performance in nonword reading; that is, the individuals with dyslexia made fewer errors. On the other hand, high-frequency rTMS stimulation over the left superior temporal gyrus resulted in faster word reading and better text reading. Interestingly, after the right inferior parietal lobule had been stimulated, the performances for nonword reading also increased. This intriguing study led

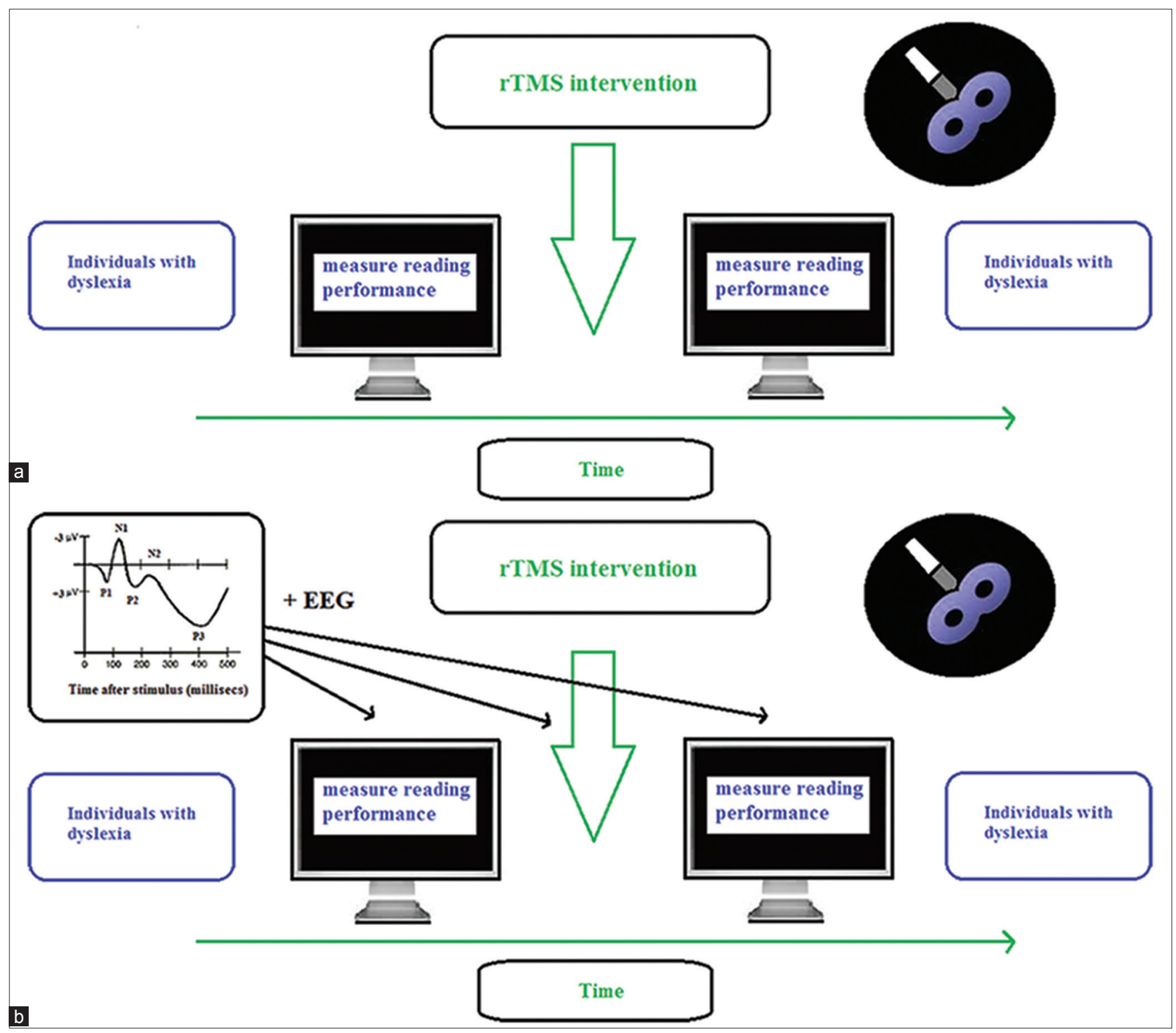

Figure 2: (a) One direction for future research aims to investigate the clinical usefulness of the rapid-rate transcranial magnetic stimulation intervention technique for treating individuals with dyslexia; (b) The second direction for future research aims to investigate the underlying neural working mechanisms (by using simultaneous electroencephalographic and transcranial magnetic stimulation) behind the rapid-rate transcranial magnetic stimulation intervention technique for treating individuals with dyslexia 
to several important insights. First, these findings indicated that in individuals with dyslexia, the left superior temporal gyrus, and the left inferior parietal lobule did not have the same role when words, nonwords, and texts were read. Second, an important finding is that not only were left-lateralized improvements found in individuals with dyslexia, as one would expect, but also right inferior parietal lobule involvement, suggesting that additional compensatory recruitment ${ }^{[57]}$ exists in this area, were found in those individuals. For the first time, these results showed that distinctive facilitation of specific neural pathways (that were previously found to be less active in individuals with dyslexia) ${ }^{[57]}$ transitorily improves the reading of words and texts, which is a fascinating finding, and could have far-reaching implications, for instance, the development of new treatments for dyslexia. ${ }^{[58]}$

\section{CONCLUSION}

The primary aim of this study was to determine the contributions that TMS has made to different reading modalities. The second goal was to investigate whether TMS might be used as a future intervention technique to overcome reading problems associated with dyslexia. We have seen that rTMS turned out to be a valuable tool for investigating questions related to reading research, both on the word and the sentence-level. Moreover, it can be applied successfully in research on dyslexia. Recently, (high-frequency) rTMS has been used as a "clinical" intervention technique for treating dyslexia by improving the reading performance by exciting underactive reading pathways in the brain. This seems to be a very promising direction for developing new and better treatments for dyslexia [Figure 2a], as long as the safety of the individuals with dyslexia can be guaranteed and strict guidelines on brain stimulation are followed. ${ }^{[60,61]}$

Moreover, a new development, the combination of brain stimulation by TMS with simultaneous electroencephalographic (EEG) imaging ${ }^{[62,63]}$ offers new prospects for research on reading and dyslexia. The integration of TMS with EEG is able to give information on the causal link between brain activity and its underlying function and cortical reactivity and its connection with other areas in the brain. More importantly, it also gives a better time window on when particular neural actions occur in the brain. ${ }^{[63]}$ Therefore, this integration of TMS with EEG will give important additional neural information on reading abnormalities in individuals with dyslexia, as well as on the efficiencies and the underlying working mechanisms of future TMS dyslexia treatments [Figure 2b].

\section{ACKNOWLEDGMENTS}

We thank Prof. Jenny Thomson, Harvard Graduate School of Education, Cambridge, MA, USA, for vivid discussions on dyslexia that eventually resulted in the writing of the present review paper. Moreover, we thank Dr. Heike Staudte from the LVR-Klinik Bedburg-Hau, Kleve, Germany, for her insights regarding the possible clinical applications of high-frequency rTMS in individuals with dyslexia.

\section{REFERENCES}

1. Bolognini N, Pascual-Leone A, Fregni F. Using non-invasive brain stimulation to augment motor training-induced plasticity. JNeuroeng Rehabil 2009;6:8.

2. Devlin JT, Watkins KE. Stimulating language: insights from TMS. Brain 2007; 130:610-22.

3. Jahanshahi M, Rothwell J. Transcranial magnetic stimulation studies of cognition: an emerging field. Exp Brain Res 2000;131:1-9.

4. Pascual-Leone A, Walsh V, Rothwell J. Transcranial magnetic stimulation in cognitive neuroscience-virtual lesion, chronometry, and functional connectivity. Curr Opin Neurobiol 2000;10:232-7.

5. Barker AT, Jalinous R, Freeston IL. Non-invasive magnetic stimulation of human motor cortex. Lancet 1985;1:1106-7.

6. Barker AT, Freestone IL, Jalinous R, Merton PA, Morton HB. Magnetic stimulation of the human brain. J Physiol 1985;369:3P.

7. Pascual-Leone A, Bartres-Faz D, Keenan JP. Transcranial magnetic stimulation: studying the brain-behaviour relationship by induction of 'virtual lesions'. Philos Trans R Soc Lond B Biol Sci 1999;354:1229-38

8. McCann UD, Kimbrell TA, Morgan CM, Anderson T, Geraci M, Benson BE, Wassermann EM, Willis MW, Post RM. Repetitive transcranial magnetic stimulation for posttraumatic stress disorder. Arch Gen Psychiatry 1998;55:276-9.

9. Pascual-Leone A, Valls-Solé J, Wassermann EM, Hallett M. Responses to rapid-rate transcranial magnetic stimulation of the human motor cortex. Brain 1994;117:847-58.

10. Pascual-Leone A, Rubio B, Pallardó F, Catalá MD. Rapid-rate transcranial magnetic stimulation of left dorsolateral prefrontal cortex in drug-resistant depression. Lancet 1996;348:233-7.

11. Zimerman M, Hummel FC. Non-invasive brain stimulation: enhancing motor and cognitive functions in healthy old subjects. Front Aging Neurosci 2010;2:149.

12. Freitas C, Farzan F, Pascual-Leone A. Assessing brain plasticity across the lifespan with transcranial magnetic stimulation: why, how, and what is the ultimate goal? Front Neurosci 2013;7:42.

13. Hamada M, Ugawa Y, Tsuji S; Effectiveness of rTMS on Parkinson's Disease Study Group, Japan. High-frequency rTMS over the supplementary motor area improves bradykinesia in Parkinson's disease: subanalysis of double-blind sham-controlled study. JNeurol Sci 2009;287:143-6.

14. Pascual-Leone A, Gates JR, Dhuna A. Induction of speech arrest and counting errors with rapid-rate transcranial magnetic stimulation. Neurology 1991;41:697-702.

15. Wada J, Rasmussen T. Intracarotid injection of sodium amytal for the lateralization of cerebral speech dominance: experimental and clinical observations. J Neurosurg 1960;17:266-82.

16. Loddenkemper T, Morris HH, Möddel G. Complications during the Wada test. Epilepsy Behav 2008;13:551-3.

17. Rösler J, Niraula B, Strack V, Zdunczyk A, Schilt S, Savolainen P, Lioumis P, Makela J, Vajkoczy P, Frey D, Picht T. Language mapping in healthy volunteers and brain tumor patients with a nove navigated TMS system: evidence of tumor-induced plasticity. Clin Neurophysiol 2014;125:526-36.

18. Epstein CM. Transcranial magnetic stimulation: language function J Clin Neurophysiol 1998;15:325-32. 
19. Broca P. New observation of aphemia caused by a lesion of the posterior half of the second and third left frontal convolutions. Bull Soc Anat Paris 1861;6:398-407.

20. Wernicke C. Der aphasische Symptomenkomplex. Breslau: Cohn and Weigert; 1874.

21. Mugnaini D, Lassi S, La Malfa G, Albertini G. Internalizing correlates of dyslexia. World J Pediatr 2009;5:255-64.

22. Cogo-Moreira H, Andriolo RB, Yazigi L, Ploubidis GB, Brandão de Ávila CR, Mari JJ. Music education for improving reading skills in children and adolescents with dyslexia. Cochrane Database Syst Rev 2012;8:CD009133.

23. Lopes J. Biologising reading problems: the specific case of dyslexia. Contemp Soc Sci 2012; 7:215-29.

24. de Beer J, Engels J, Heerkens Y, van der Klink J. Factors influencing work participation of adults with developmental dyslexia: a systematic review. BMC Public Health 2014;14:77.

25. Young AW. Methodological and theoretical bases of visual hemifield studies. In: Beaumont JG, editor. Divided Visual Field Studies of Cerebral Organization. London: Academic Press; 1982.

26. Ellis AW, Young AW, Anderson C. Modes of word recognition in the left and right cerebral hemispheres. Brain Lang 1988;35:254-73.

27. Skarratt $P A$, Lavidor M. Magnetic stimulation of the left visual cortex impairs expert word recognition. J Cogn Neurosci 2006;18:1749-58.

28. Ellis AW, Brooks J, Lavidor M. Evaluating a split fovea model of visual word recognition: effects of case alternation in the two visual fields and in the left and right halves of words presented at the fovea. Neuropsychologia 2005;43:1128-37.

29. Lavidor M, Hayes A, Shillcock R, Ellis AW. Evaluating a split processing model of visual word recognition: effects of orthographic neighborhood size. Brain Lang 2004;88:312-20.

30. Ellis AW, Brysbaert M. Split fovea theory and the role of the two cerebral hemispheres in reading: a review of the evidence. Neuropsychologia 2010;48:353-65.

31. Brysbaert M. The importance of interhemispheric transfer for foveal vision: a factor that has been overlooked in theories of visual word recognition and object perception. Brain Lang 2004;88:259-67.

32. Hsiao JH, Shillcock R, Lavidor M. A TMS examination of semantic radical combinability effects in Chinese character recognition. Brain Res 2006;1078:159-67.

33. Stoeckel C, Gough PM, Watkins KE, Devlin JT. Supramarginal gyrus involvement in visual word recognition. Cortex 2009;45:1091-6.

34. Price CJ, Moore CJ, Humphreys GW, Wise RJ. Segregating semantic from phonological processes during reading. $J$ Cogn Neurosci 1997;9:727-33.

35. Nakamura K, Hara N, Kouider S, Takayama Y, Hanajima R, Sakai K, Ugawa Y. Task-guided selection of the dual neural pathways for reading. Neuron 2006;52:557-64

36. Tomasino B, Fink GR, Sparing R, Dafotakis M, Weiss PH. Action verbs and the primary motor cortex: a comparative TMS study of silent reading, frequency judgments, and motor imagery. Neuropsychologia 2008;46:1915-26.

37. Hoffman P, Jefferies E, Lambon Ralph MA. Ventrolateral prefrontal cortex plays an executive regulation role in comprehension of abstract words: convergent neuropsychological and repetitive TMS evidence. J Neurosci 2010;30:15450-6.

38. Binder JR, Desai RH, Graves WW, Conant LL. Where is the semantic system? A critical review and meta-analysis of 120 functional neuroimaging studies. Cereb Cortex 2009;19:2767-96.

39. Manenti R, Cappa SF, Rossini PM, Miniussi C. The role of the prefrontal cortex in sentence comprehension: an rTMS study. Cortex 2008:44:337-44.

40. Caplan D, Vijayan S, Kuperberg G, West C, Waters G, Greve D, Dale AM. Vascular responses to syntactic processing: event-related fMRI study of relative clauses. Hum Brain Mapp 2002;15:26-38.

41. Hashimoto R, Sakai KL. Specialization in the left prefrontal cortex for sentence comprehension. Neuron 2002;35:589-97.
42. Cacciari C, Bolognini N, Senna I, Pellicciari MC, Miniussi C, Papagno C. Literal, fictive and metaphorical motion sentences preserve the motion component of the verb: a TMS study. Brain Lang 2011;119:149-57.

43. Scorolli C, Jacquet PO, Binkofski F, Nicoletti R, Tessari A, Borghi AM. Abstract and concrete phrases processing differentially modulates cortico-spinal excitability. Brain Res 2012;1488:60-71.

44. Acheson DJ, Hagoort P. Stimulating the brain's language network: syntactic ambiguity resolution after TMS to the inferior frontal gyrus and middle temporal gyrus. J Cogn Neurosci 2013;25:1664-77.

45. Goswami U. Sensory theories of developmental dyslexia: three challenges for research. Nat Rev Neurosci 2015;16:43-54.

46. Nelson JM, Lindstrom W, Foels PA. Test anxiety among college students with specific reading disability (Dyslexia): nonverbal ability and working memory as predictors. J Learn Disabil 2015;48:422-32.

47. Hadzibeganovic T, van den Noort M, Bosch P, Perc M, van Kralingen R, Mondt K, Coltheart M. Cross-linguistic neuroimaging and dyslexia: a critical view. Cortex 2010;46:1312-6.

48. Siegel LS. Perspectives on dyslexia. Paediatr Child Health 2006;11:581-7.

49. Boets B, Op de Beeck HP, Vandermosten M, Scott SK, Gillebert CR, Mantini D, Bulthe J, Sunaert S, Wouters J, Ghesquiere P. Intact but less accessible phonetic representations in adults with dyslexia. Science 2013;342:1251-4.

50. Bruck M. Word-recognition skills of adults with childhood diagnoses of dyslexia. Dev Psychol 1990;26:439-54.

51. Shaywitz SE, Fletcher JM, Holahan JM, Shneider AE, Marchione KE Stuebing KK, Francis DJ, Pugh KR, Shaywitz BA. Persistence of dyslexia: the Connecticut Longitudinal Study at adolescence. Pediatrics 1999;104:1351-9.

52. Shaywitz SE. Dyslexia. N Engl J Med 1998;338:307-12

53. Habib M, Giraud K. Dyslexia. Handb Clin Neurol 2013;111:229-35

54. Joly-Pottuz B, Mercier M, Leynaud A, Habib M. Combined auditory and articulatory training improves phonological deficit in children with dyslexia. Neuropsychol Rehabil 2008;18:402-29.

55. Coslett HB, Monsul N. Reading with the right hemisphere: evidence from transcranial magnetic stimulation. Brain Lang 1994;46:198-211.

56. Frye RE, Rotenberg A, Ousley M, Pascual-Leone A. Transcranial magnetic stimulation in child neurology: current and future directions. J Child Neurol 2008;23:79-96.

57. Hoeft F, McCandliss BD, Black JM, Gantman A, Zakerani N, Hulme C, Lyytinen H, Whitfield-Gabrieli S, Glover GH, Reiss AL, Gabrieli JD. Neural systems predicting long-term outcome in dyslexia. Proc Natl Acad Sci U S A 2011;108:361-6.

58. Costanzo F, Menghini D, Caltagirone C, Oliveri M, Vicari S. How to improve reading skills in dyslexics: the effect of high frequency rTMS. Neuropsychologia 2013;51:2953-9.

59. Costanzo F, Menghini D, Caltagirone C, Oliveri M, Vicari S. High frequency rTMS over the left parietal lobule increases non-word reading accuracy. Neuropsychologia 2012;50:2645-51.

60. Gutchess A. Plasticity of the aging brain: new directions in cognitive neuroscience. Science 2014;346:579-82.

61. van den Noort M, Lim S, Bosch P. Recognizing the risks of brain stimulation. Science 2014;346:1307.

62. Thut G, Pascual-Leone A. Integrating TMS with EEG: how and what for? Brain Topogr 2010;22:215-8.

63. Miniussi $C$, Thut $G$. Combining TMS and EEG offers new prospects in cognitive neuroscience. Brain Topogr 2010;22:249-56.

Cite this article as: Noort Mv, Struys E, Bosch P. Transcranial magnetic stimulation research on reading and dyslexia: a new clinical intervention technique for treating dyslexia?. Neuroimmunol Neuroinflammation 2015;2(3):145-52.

Source of Support: Nil. Conflict of Interest: No.

Received: 05-11-2014; Accepted: 23-12-2014 